Cathy Alberda

Leah Gramlich

Naomi Jones

Khursheed Jeejeebhoy

Andrew G. Day

Rupinder Dhaliwal

Daren K. Heyland

\section{The relationship between nutritional intake and clinical outcomes in critically ill patients: results of an international multicenter observational study}

Published online: 7 August 2009

(C) Copyright jointly hold by Springer and ESICM 2009

The online version of the original article can be found under doi:10.1007/s00134-009-1567-4.

\section{Alberda · L. Gramlich}

Alberta Health Services Edmonton, Edmonton, AB, Canada e-mail: cathy.alberda@capitalhealth.ca

\section{Gramlich}

University of Alberta, Edmonton, AB, Canada

e-mail: leah.gramlich@ualberta.ca

N. Jones · A. G. Day · R. Dhaliwal · D. K. Heyland ( Clinical Evaluation Research Unit, Kingston General Hospital, Angada 4, 76 Stuart Street, Kingston, ON K7L 2V7, Canada e-mail: dkh2@queensu.ca

Tel.: +1-613-5496666

Fax: +1-613-5482428

N. Jones

e-mail: jonesn@kgh.kari.net

\section{A. G. Day}

e-mail: daya@kgh.kari.net

R. Dhaliwal

e-mail: dhaliwar@kgh.kari.net

N. Jones · A. G. Day · D. K. Heyland

Department of Community Health and Epidemiology,

Queen's University, Kingston, ON, Canada
K. Jeejeebhoy

St. Michael's Hospital, Toronto, ON, Canada e-mail: khushjeejeebhoy@compuserve.com

\section{K. Jeejeebhoy}

Department of Medicine, University of Toronto, Toronto, ON, Canada

D. K. Heyland

Department of Medicine, Queen's University, Kingston, ON, Canada

\section{Erratum to: Intensive Care Med DOI 10.1007/s00134-009-1567-4}

In the abstract and the first sentence of the results the article reports that 167 ICUs from 37 countries across 5 continents participated in the study. The number of ICUs and continents were reported correctly, but these came from 21 rather than 37 countries.

The authors apologize for this error. 